African Crop Science Journal by African Crop Science Society is licensed under a Creative Commons Attribution 3.0 Uganda License. Based on a work at www.ajol.info/ and www.bioline.org.br/cs DOI: http://dx.doi.org/10.4314/acsj.v23i4.8

\title{
EFFICIENT SCREENING PROCEDURE FOR BLACK SIGATOKA DISEASE OF BANANA
}

\author{
A. KUMAKECH ${ }^{1,2}$, H.J. LYNGS JØRGENSEN ${ }^{3}$, R. EDEMA ${ }^{2}$ and P. OKORI ${ }^{2}$ \\ ${ }^{1}$ National Agricultural Research Organization (NARO), Ngetta Zonal Agricultural Research and Development \\ Institute, P. O. Box 52, Lira, Uganda \\ ${ }^{2}$ Department of Agricultural Production, Makerere University, P. O. Box 7062, Kampala, Uganda \\ ${ }^{3}$ University of Copenhagen, Faculty of Science, Department of Plant and Environmental Sciences, \\ Thorvaldsensvej 40, DK-1871 Frederiksberg C, Denmark \\ Corresponding author: kumalfred@gmail.com
}

(Received 16 October, 2015; accepted 20 November, 2015)

\begin{abstract}
Current methods for screening for reaction of Mycosphaerella fijiensis are mostly field based and subject to variability caused by weather conditions. The objective of this study was to develop an efficient screening procedure for black sigatoka disease in order to provide a reliable controlled environment screening method. A fragmented mycelia-based infection system was developed using weighed mycelia suspensions, in $0.18 \%$ water agar. Consistent and repeatable black sigatoka infection was achieved in cv. Gross Michel as a reference susceptible cultivar. The infection system developed was used to validate screenhouse reaction of banana genotypes to $M$. fijiensis. Three East African highland genotypes (AAA-EA), one plantain genotype (ABB), two dessert (AAB and AAA) and one hybrid genotype (AAAA) were tested. Inoculum of M. fijiensis was adjusted to $15 \mathrm{mg} \mathrm{ml}^{-1}$ fragmented mycelium and applied to the abaxial surfaces of the first two open leaves. Plants were evaluated for 6 weeks post inoculation (PI). Significant differences in the response of the different genotypes, to $M$. fijiensis infection were observed at 3, 4, 5 and 6 weeks PI. All East African highland and dessert genotypes were susceptible. M9 hybrid and Psang awak (ABB) expressed resistance, characterised by high disease incubation period and slow rate of symptom development, with Psanag awak being the most resistant. Artificial inoculation of in vitro plants with weighed fragmented mycelial suspension, was practicable for determining resistance to $M$. fijiensis. This is the first report demonstrating that use of weighed fragmented mycelial inoculum spread over the entire leaf surface, can be used to quantitatively assess reaction of banana genotypes to $M$. fijiensis under screenhouse conditions.
\end{abstract}

Key Words: Ascomycete, Black leaf streak, Mycosphaerella fijiensis Musa sp.

\section{RÉSUMÉ}

Les méthodes actuelles de dépistage de Mycosphaerella fijiensis sont essentiellement basées sur des évaluations dans le champ et sont souvent sujets à des variabilités climatiques. L'objectif de cette étude était de développer une procédure efficace de dépistage de la maladie foliaire du bananier Sigatoka dans le but de proposer une méthode de dépistage non influencée par l'environnement. Un système d'infection a été développé en se servant de mycélium en suspension dans $0,18 \%$ de solution agar. Des infections consistantes et répétées ont été réalisées in cv. La variété Gross Michel a été utilisée comme référence susceptible. Le système d'infection développé a été utilisé pour valider la réaction des accessions de bananiers en serre à M. fijiensis. Trois génotypes de bananiers adaptés aux hautes altitudes en Afrique de l'Est (AAA-EA), un génotype de type plantain (ABB), deux déserts (AAB and AAA) et un hybride (AAAA) ont été testés. Des inocula de $M$. fijiensis ont été doses à $15 \mathrm{mg} \mathrm{ml}-1$ et appliqués sur la face dorsale des deux premières feuilles ouvertes. Les plants ont été évalués pendant 6 semaines après inoculation (PI). Des différences significatives ont été observées dans les réponses des génotypes à 
l'infection à différents stages après inoculation (3, 4,5 et 6 semaines) de $M$. fijiensis. Tous les génotypes de haute altitude et les déserts ont été révélés susceptibles. L'hybride M9 et Psang awak (ABB) se sont montrés résistants, ils sont caractérisés par une longue période d'incubation et un taux bas de développement de symptômes, Psanag awak s'est révélé le plus résistant. L'inoculation artificielle in vitro des plants avec des suspensions de fragments mycéliens, a été pratique dans la détermination de la résistance à $M$. fijiensis. Ceci est le premier résultat d'étude scientifique ayant démontré que cette technique peut être utilisée pour l'évaluation de la réaction des génotypes de bananiers à l'infection de M. fijiensis dans des conditions d'expériences en serre..

Mots Clés: Ascomycete, Maladie foliaire du bananier, Mycosphaerella fijiensis, Musa sp.

\section{INTRODUCTION}

Black Sigatoka, caused by the ascomycete Mycosphaerella fijiensis M. Morelet, anamorph: Paracercospora fijiensis (M. Morelet) Deighton, is considered the most costly and destructive leaf spot disease of banana (Musa sp.), affecting all cultivars that belong to the AAAand AAB genome groups (Marin et al., 2003; Tushemereirwe et al., 2004; Churchil, 2011). Since its first report in 1963 in the island of Fiji in South Pacific, the disease has spread to various bananaproducing regions of the world (Carlier et al., 2000), including East Africa, the secondary centre, for diversity for the unique East African highland banana (EA-AAA) genome group (Tushemereirwe et al., 2004).

Black sigatoka affects banana leaves, reducing photosynthetic area, and ultimately fruit yield, by inducing premature ripening. The tall stature of banana plants (i.e. up to $3 \mathrm{~m}$ ), presents challenges in screening for foliar disease reaction, further compounding efforts to manage the disease. Yet, the current approaches for screening for reaction of $M$. fijiensis are mostly field borne and subject to variability caused by weather and other extraneous sources. This has complicated early selection of of promising genotypes during breeding, inspite of the advancement in plant tissue culture that provides thousands of plantlets for rapid assays. As such, there is demand for reliable controlled environment screening methods, that exploit the high through put in vitro techniques; while maintaining the rigour, required for banana pathology and breeding. Controlled environment based approaches also permit the use of different pathotypes as well as supporting cytological and biochemical studies of the host-pathogen interactions.
In the case of banana, various attempts at using controlled environments have explored the use of smaller plantlets, raised through tissue culture or the use of detached leaf assays (Capo et al., 2003; Twizeyimana et al., 2007). In both approaches, use of mycelium or conidial suspensions leads to full disease symptom development, with higher rates noted with mycelial fragments, compared to inoculations with conidial suspensions (Twizeyimana et al., 2007).

Twizeyimana et al. (2007), however, recommended the use of conidial suspensions, due to difficulty of quantification and standardisation of mycelial suspensions. Thus, the use of mycelilal suspension, while promising has been limited so far. In the case of leaf disc assays that require small culture tubes and media, maintainance of excised leaf discs in a nonsenescent state, for several months to evaluate disease reaction is difficult (Townley et al., 2001). This, coupled with the fungal colonisation of the media, further limits its use.

Thus, inspite of the advances in controlled environment-based screening techniques for black sigatoka, evaluation of banana for reaction to black sigatoka is routinely done in the field, under varied pathogen pressure, climatic conditions and very slow progress (Foure et al., 2000). Field evaluation is only useful for germplasm characterisation but not sufficient to identify components of partial resistance at various stages of black sigatoka infection cycle (Balint-Kurti et al., 2001).

Production of conidia by $M$. fijiensis requires 10 to 14 days of growth under relatively stringent conditions (Carlier et al., 2000). The fact that conidial production is highly variable, and in some cases significantly impaired by culture media and environmental requirements (Jacome and Schuh, 1993), further compounds the need for a 
very potent source of inoculum. The objective of this study was to develop a simple methodology for assessing the reaction of banana plantlets to M. fijiensis using weighed and fragmented mycelium.

\section{MATERIALS AND METHODS}

Culture media. Six culture media, namely, potato dextrose agar (PDA, HIMEDIA, India), Malt extract agar (OXOID, UK), AFPA Base (OXOID, UK), Czapak Dox Agar (OXOID, UK), Nutrient agar (Sigma Aldrich, USA) and Yeast Extract (Sigma Aldrich, USA), were used in this study. Agar disks, $3 \mathrm{~mm}$ in diameter, from actively growing PDA cultures of $M$. fijiensis were aseptically placed at the centre of the different media, in a $9 \mathrm{~cm}$ diameter Petri-dish. The inoculated plates were sealed and incubated at $25^{\circ} \mathrm{C}$ for 28 days. Colony growth was determined on the basis of linear dimensions using, a mathematical ruler. The mean diameter of the mycelial growth was recorded, and mycelium from each plate was scraped off with a sterile scalpel and weighed on sterile filter paper to determine mycelium weight prior to use in inoculum preparation.

Inoculum types and concentrations. Agar disks, $3 \mathrm{~mm}$ in diameter, from actively growing potato dextrose agar (PDA) cultures of three local $M$. fijiensis isolates (Mak01, Mak02 and Kaw10) grown at $25^{\circ} \mathrm{C}$ ( $<15$ days old), were aseptically transferred to malt extract plates using a sterile scarpel. A total of 25 plates were prepared for each isolate. The inoculated plates were sealed and incubated at $25{ }^{\circ} \mathrm{C}$ for 14 days. Mycelium from each isolate were scraped off with a sterile scalpel, bulked and weighed in a pre-weighed sterile filter paper. The weighed mycelium was fragmented in a blender (commercial blender, USA) at full speed for 1 or $3 \mathrm{~min}$. A master mycelium suspension was prepared for each isolate, and serial dilutions to final concentrations of 15,10 and $5 \mathrm{mg} \mathrm{ml}^{-1}$ were made.

Two independent inoculation experiments were conducted in the screenhouse at Makerere University. The experiments involved the inoculation of two months old tissue culture banana plants with fragmented mycelium of the three isolates at concentrations of 15,10 and 5 $\mathrm{mg} \mathrm{ml}^{-1}$ of steriled $0.18 \%$ water agar. Inoculum was applied to plants of Gross Michel (Bogoya), a standard susceptible reference clone for Black Sigatoka (Tushemereirwe et al., 2004), and $0.5 \mathrm{ml}$ of each inoculum was applied on the abaxial surfaces of the first and second fully unfolded leaves, until run-off, using a painter's brush. Each treatment was administered to nine banana plantlets.

In both experiments, inoculated plantlets were incubated in a humidity chamber built using a timber frame covered with a translucent polythene sheet, at a temperature of $28-31^{\circ} \mathrm{C}$ and continuous relative humidity of approximately $90 \%$, for 48 hours.

High relative humidity (approximately 90\%) was provided by keeping 10 litres of water in two open 51 plastic beakers. Temperature was monitored using a wall thermometer, placed inside the chamber. After the initial incubation, plants were transferred to a bench in the screenhouse, and examined weekly for the first two weeks, and subsequently daily for symptom development on both leaf surfaces.

Data on severity ratings (number of lesions), lesion characteristics, and incubation and latency periods were recorded. The number of lesions was used to calculate Area under Disease Progress Curve (AUDPC) (Madden et al., 2007) and AUDPC values subjected to analysis of variance.

Screenhouse validation. The reactions of three East African highland banana genotypes, two plantain genotypes, two dessert genotypes and one hybrid (Table 1) were compared with cvs. Bogoya and Kayinja (a standard resistant clone for Black Sigatoka) in two independent experiments. A concentration of $15 \mathrm{mg} \mathrm{ml}^{-1}$ mycelium of $M$. fijiensis isolate (Mak 01), was used as inoculum. In both experiments, 3 month old plantlets were inoculated with $1 \mathrm{ml}$ of $15 \mathrm{mg}$ $\mathrm{ml}^{-1}$ mycelium. Inoculated plantlets were incubated as described above. After $48 \mathrm{hr}$, plants were removed and placed in a screenhouse, and examined weekly for the first two weeks, and subsequently daily for symptoms on both leaf surfaces. A 1-5 scale (Table 2) developed by Fullerton and Olsen (1995) was used to evaluate 
TABLE 1. Banana genotypes and their genome groups used for screenhouse validation of reaction of banana to $M$. fijiensis at Makerere University Agricultural Research Institute, Kabanyolo in Uganda

\begin{tabular}{lcl}
\hline Genotype & Genome group & Use \\
\hline Mbwazirume & AAA-EA & Cooking \\
Kibuzi & AAA-EA & Cooking \\
Nfuuka & AAA-EA & Cooking \\
Gonja & AAB & Roasting/ beer/ cooking \\
Kayinja & ABB & Roasting/ beer/ cooking \\
Ndiizi & AB & Cooking/dessert \\
Bogoya & AAA & Dessert \\
M9 hybrid & AAA & Cooking \\
\hline
\end{tabular}

symptom development and the classification of genotypes according to the stage of symptom development.

Experimental design and data analysis. All experiments were established following a randomised complete block design, with four replications and repeated at least once. Data on severity ratings (assessed using number of lesions), lesion characteristics, incubation and latent periods were recorded. The number of lesions was used to calculate Areas Under Disease Progress Curve (AUDPC) (Madden et al., 2007) prior to statistical analysis. All

TABLE 2. Scale used to evaluate symptom development and the classification of genotypes according to the stage of symptom development

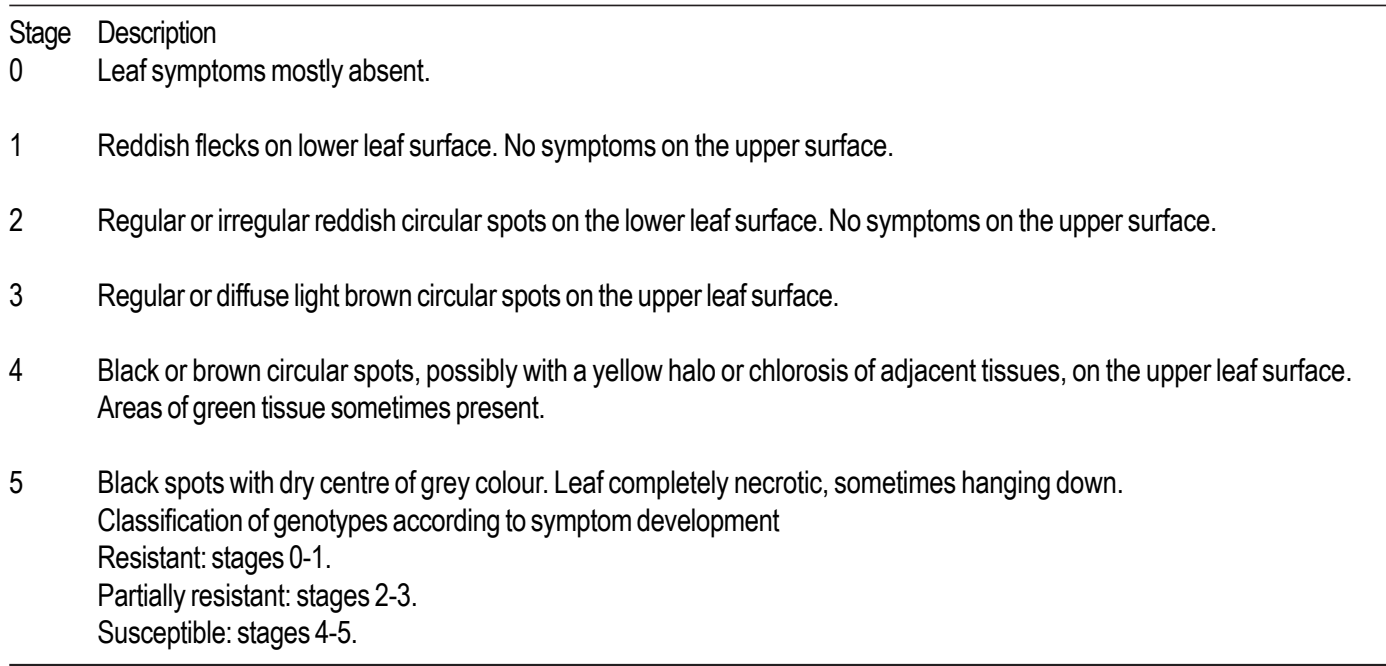

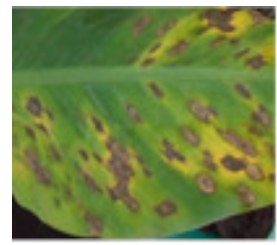

A

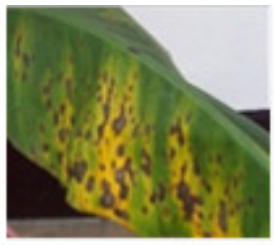

B

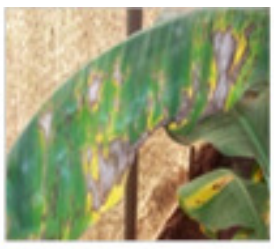

C

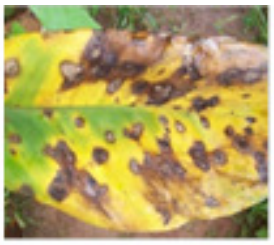

D

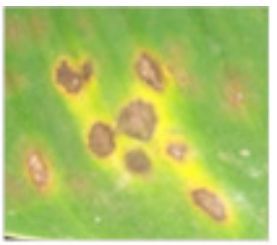

E

Figure 1. Black Sigatoka lesion types on AAA-EA genome ( $A=$ Mbwazirume, $B=$ Mpologoma, $C=$ Musakala, $D=N f u u k a)$ and E=M9 Hybrid (AAAA). 
experimental data were subjected to analysis of variance (ANOVA) at $\mathrm{P}<0.05$. Data were normalised, following tests for normality. All data analysis were performed using PC-SAS, version 9.3 (SAS Institute Inc., Cary, NC, USA).

\section{RESULTS}

Virulence of isolates. The first symptoms for isolates Mak01, Mak02, and Kaw10 became visible on average 23 days after inoculation (DAI), in the first and $25 \mathrm{DAI}$ in the second experiment. In both assays, symptoms appeared as light brown streaks that later darkened and enlarged, assuming the typical pattern of Black Sigatoka lesions (Fig. 2). Symptoms caused by the three isolates, progressed at the same rate. By the end of each experiment (42 DAI), the lesions caused by the three isolates were extensive, covering about $80 \%$ or more of each inoculated leaf, especially in plants inoculated with mycelium suspensions of $15 \mathrm{mg} \mathrm{ml}^{-1}$.

Inoculation of emerging leaves, on average had early disease development (21 DAI). No significant differences in levels of disease caused by the three isolates, in the first and second experiments, was found $(\mathrm{P}>0.05)$. However, the effect of fragmentation time, mycelial concentration and interaction between concentration, fragmentation time and mycelium amount had substantial impacts on the final disease severity scores (Table 3). Since isolate effects was not significant, dose-response line estimates were not made.

The isolate of M. fijiensis (Kaw10) produced vegetative mycelial growth on all six culture media

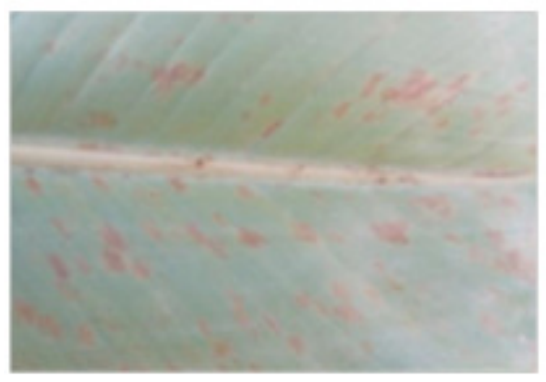

A
(Table 4). Significant differences were observed between the six culture media for vegetative mycelial colonisation and mycelial weight. Total vegetative mycelial colonisation ranged from 22.6 $\mathrm{mm}$ for malt extract, to $4.2 \mathrm{~mm}$. More mycelium was produced on malt extract agar $(22.6 \mathrm{~mm})$, than PDA (Table 4).

Validation of reaction banana genotypes. The time from artificial inoculation of plants, to the appearance of the first symptom differed among the genotypes tested, and the incubation period varied between 21 and 42 days (Table 5). Streaks appeared about at 23 days for susceptible cultivars (Grosh Michel, Nfuuka, Mbwazirume, Gonja, Mpologoma, and Kibuzi), and at 37 for partially resistant cultivars (Table 5).

Highly significant differences $(\mathrm{P}<0.001)$ in latent period were found in all banana cultivars (Table 5). The latent period varied from 8.33 to 12.67 days after symptom appearance in susceptible cultivars to 22.33 to 26.17 days for resistant cultivars.

Disease severity increased over time as expected (Fig. 3). The highest disease severity was recorded on the leaves of Gross Michel, Gonja, Kibuzi and Mbwazirume; whereas M9 Hybrid and Kayinja had the lowest disease severity (Table 6). The necrotic spots were slightly circular, possibly because young plants derived from tissue culture have limited vein development and the lesions tended to be spherical (Fig. 1). Disease severity under screenhouse condition was more on East African Highland bananas and less on M9 hybrid (Fig. 3).

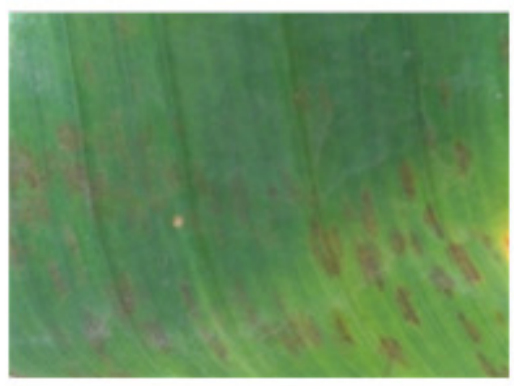

B

Figure 2. Light brown streaks caused by fragmented mycelia on the underside of banana leaf (A), that later darkened and enlarged, assuming the typical pattern of Black Sigatoka lesions on the upper leaf surface.(B). 
TABLE 3. Comparison of mean values of Area Under Disease Progress Curve (AUDPC) for effect of mycelium amounts and fragmentation treatments on Black Sigatoka development for a study conducted in central Uganda

\begin{tabular}{|c|c|c|c|}
\hline \multirow[t]{2}{*}{ M.fijiensis isolate } & \multirow[t]{2}{*}{ Treatment combinations } & \multicolumn{2}{|c|}{ Mean values of AUDPC } \\
\hline & & Experiment 1 & Experiment 2 \\
\hline Mak01 & 3min fragmentation + $15 \mathrm{mg} \mathrm{m}^{-1}$ mycelium concentration & 95.8 & 101.2 \\
\hline Mak01 & 3 min fragmentation $+10 \mathrm{mg} \mathrm{ml}^{-1}$ mycelium concentration & 71.4 & 73.7 \\
\hline Mak01 & 3 min fragmentation $+5 \mathrm{mg} \mathrm{ml}^{-1} \quad$ mycelium concentration & 62.3 & 59.7 \\
\hline Mak01 & 1 min fragmentation $+15 \mathrm{mg} \mathrm{ml}^{-1} \quad$ mycelium concentration & 42.9 & 49.2 \\
\hline Mak01 & 1 min fragmentation $+10 \mathrm{mg} \mathrm{m}^{-1}$ mycelium concentration & 42.0 & 46.0 \\
\hline Mak01 & 1 min fragmentation $+5 \mathrm{mg} \mathrm{ml}^{-1}$ mycelium concentration & 16.8 & 23.7 \\
\hline Mak02 & 3 min fragmentation $+15 \mathrm{mg} \mathrm{ml}^{-1}$ mycelium concentration & 89.2 & 93.1 \\
\hline Mak02 & 3 min fragmentation $+10 \mathrm{mg} \mathrm{ml}^{-1}$ mycelium concentration & 79.2 & 75.9 \\
\hline Mak02 & 3 min fragmentation $+5 \mathrm{mg} \mathrm{ml}^{-1}$ mycelium concentration & 63.9 & 69.1 \\
\hline Mak02 & 1 min fragmentation $+15 \mathrm{mg} \mathrm{ml}^{-1}$ mycelium concentration & 41.4 & 47.4 \\
\hline Mak02 & 1 min fragmentation $+10 \mathrm{mg} \mathrm{ml}^{-1}$ mycelium concentration & 39.0 & 42.7 \\
\hline Mak02 & 1 min fragmentation $+5 \mathrm{mg} \mathrm{ml}^{-1}$ mycelium concentration & 21.6 & 19.2 \\
\hline Kaw10 & 3 min fragmentation $+15 \mathrm{mg} \mathrm{ml}^{-1}$ mycelium concentration & 90.6 & 96.3 \\
\hline Kaw10 & 3 min fragmentation + $10 \mathrm{mg} \mathrm{ml}^{-1}$ mycelium concentration & 78.9 & 72.9 \\
\hline Kaw10 & 3 min fragmentation $+5 \mathrm{mg} \mathrm{ml}^{-1}$ mycelium concentration & 53.7 & 54.3 \\
\hline Kaw10 & 1 min fragmentation $+15 \mathrm{mg} \mathrm{m}^{-1}$ mycelium concentration & 45.9 & 50.5 \\
\hline Kaw10 & 1 min fragmentation + $10 \mathrm{mg} \mathrm{ml}^{-1}$ mycelium concentration & 37.2 & 42.9 \\
\hline Kaw10 & 1 min fragmentation $+5 \mathrm{mg} \mathrm{ml}^{-1}$ mycelium concentration & 19.6 & 16.8 \\
\hline$P$ values & & $<0.001$ & $<0.001$ \\
\hline LSD $(5 \%)$ & & 15.37 & 13.76 \\
\hline
\end{tabular}

TABLE 4. Culture Media Influence on vegetative growth and mycelial weight of Mycosphaerella fijiensis

\begin{tabular}{|c|c|c|c|c|}
\hline \multirow[t]{3}{*}{ Culture media } & \multicolumn{4}{|c|}{ Mean values } \\
\hline & \multicolumn{2}{|c|}{ Mycelial growth (mm) } & \multicolumn{2}{|c|}{ Mycelial weight (g) } \\
\hline & Experiment 1 & Experiment 2 & Experiment 1 & Experiment 2 \\
\hline Malt extractAgar & 22.6 & 24.3 & 0.333 & 0.345 \\
\hline AFPA Base & 4.2 & 4.2 & 0.000 & 0.000 \\
\hline Czapak Dox Agar & 18.6 & 16.5 & 0.023 & 0.027 \\
\hline Nutrientagar & 4.5 & 4.8 & 0.000 & 0.000 \\
\hline Yeast Extract & 17.7 & 16.9 & 0.036 & 0.042 \\
\hline PDA (control) & 21.3 & 20.0 & 0.098 & 0.116 \\
\hline$P$ values & $<0.001$ & $<0.001$ & $<0.0001$ & $<0.0001$ \\
\hline LSD (5\%) & 1.899 & 2.467 & 0.0319 & 0.0467 \\
\hline
\end{tabular}


TABLE 5. Incubation period and latency period for banana cultivars challenge inoculated with $15 \mathrm{mg} / \mathrm{ml}$ fragmented mycelium suspension under screenhouse condition

\begin{tabular}{|c|c|c|c|c|c|}
\hline \multirow[t]{3}{*}{ Banana cultivar } & \multirow[t]{3}{*}{ Genome group } & \multicolumn{4}{|c|}{ Mean values (days) } \\
\hline & & \multicolumn{2}{|c|}{ Incubation period } & \multicolumn{2}{|c|}{ Latent period } \\
\hline & & Experiment 1 & Experiment 2 & Experiment 1 & Experiment 2 \\
\hline Mbwazirume & AAA-EA & 21.67 & 23.67 & 9.67 & 9.67 \\
\hline Mpologoma & AAA-EA & 22.33 & 22.67 & 10.33 & 10.67 \\
\hline Kibuzi & AAA-EA & 21.00 & 22.33 & 9.33 & 8.33 \\
\hline Nfuuka & AAA-EA & 21.67 & 22.67 & 10.33 & 9.00 \\
\hline Gonja & $\mathrm{AAB}$ & 21.33 & 23.67 & 9.33 & 10.67 \\
\hline Kayinja & $A B B$ & 41.67 & 40.33 & 27.00 & 28.67 \\
\hline Ndiizi & $A B$ & 33.33 & 28.33 & 12.00 & 12.67 \\
\hline Gross Michel & AAA & 21.67 & 23.67 & 8.00 & 9.00 \\
\hline M9 hybrid & AAAA & 32.67 & 33.33 & 15.00 & 16.00 \\
\hline$P$ values & & $<.001$ & $<.001$ & $<.001$ & $<.001$ \\
\hline LSD (5\%) & & 3.01 & 1.98 & 2.54 & 3.03 \\
\hline
\end{tabular}

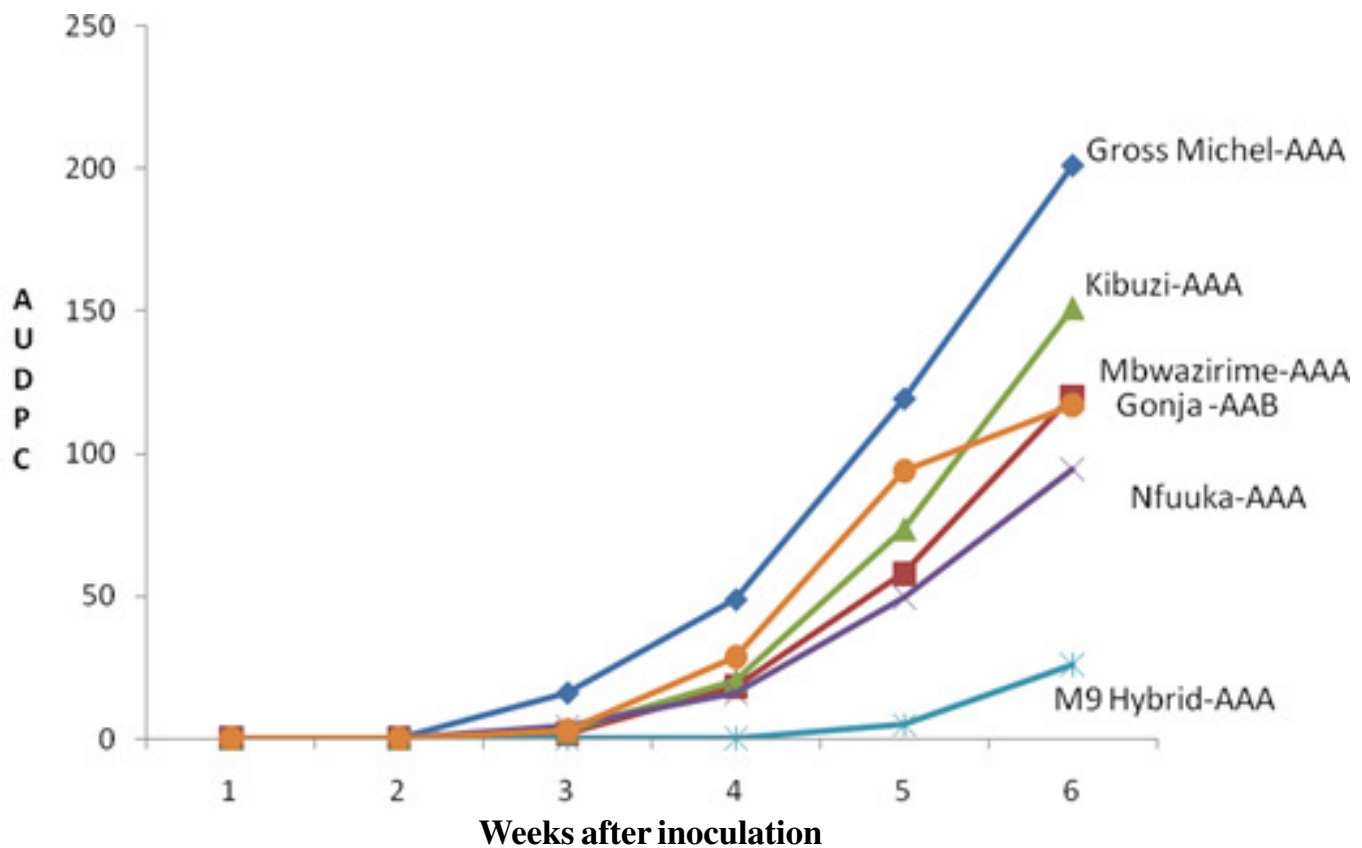

Figure 3. Variation in Black Sigatoka response among banana cultivars challenge inoculated with $15 \mathrm{mg} / \mathrm{ml}$ fragmented mycelia under screenhouse conditions. 
TABLE 6. Comparison of AUDPC mean values of banana cultivars inoculated with fragmented mycelia under screen house condition

\begin{tabular}{|c|c|c|c|c|c|c|c|c|}
\hline \multirow[t]{3}{*}{ Banana cultivar } & \multicolumn{8}{|c|}{ AUDPC values } \\
\hline & \multicolumn{4}{|c|}{ Experiment 1} & \multicolumn{4}{|c|}{ Experiment 2} \\
\hline & Week 3 & Week 4 & Week 5 & Week 6 & Week 3 & Week 4 & Week 5 & Week 6 \\
\hline Mbwazi. & 4.75 & 21.00 & 66.25 & 133.38 & 1.75 & 18.13 & 57.88 & 120.13 \\
\hline Kibuzi & 3.13 & 21.38 & 75.75 & 151.25 & 2.50 & 20.38 & 73.50 & 151.13 \\
\hline Nfuuka & 5.63 & 18.00 & 49.50 & 93.63 & 4.13 & 16.00 & 48.38 & 94.50 \\
\hline Gonja & 9.25 & 36.13 & 101.13 & 183.38 & 2.75 & 28.75 & 94.00 & 175.25 \\
\hline Kayinja & 0.00 & 0.00 & 0.00 & 0.00 & 0.00 & 0.000 .00 & 0.00 & 0.00 \\
\hline Ndiizi & 0.00 & 0.00 & 27.75 & 94.00 & 0.00 & 00.00 & 28.00 & 94.38 \\
\hline Bogoya & 11.00 & 40.88 & 108.63 & 191.13 & 16.00 & 48.75 & 119.25 & 201.13 \\
\hline M9 hyb. & 0.00 & 0.00 & 3.375 & 20.25 & 0.00 & 0.00 & 4.75 & 24.75 \\
\hline$P$ value & 0.0047 & $<0.0001$ & $<0.0001$ & $<0.0001$ & $<0.0001$ & $<0.0001$ & $<0.0001$ & $<0.0001$ \\
\hline LSD (5\%) & 5.4223 & 10.413 & 16.311 & 20.141 & 2.9700 & 4.6349 & 11.2800 & 17.7660 \\
\hline
\end{tabular}

TABLE 7. Reaction of seven Musa cultivars to artificial inoculation with $15 \mathrm{mg} \mathrm{ml}^{-1}$ fragmented mycelial suspensions of Mycosphaerella fijiensis in the screen house

\begin{tabular}{lllc}
\hline \multirow{2}{*}{ Cultivar } & Screenhouse reaction & \multicolumn{2}{c}{ Symptom development Stage } \\
\cline { 3 - 4 } & & 35 dai & 42 dai \\
\hline Mbwazirume & Susceptible & 5 & 5 \\
Bogoya & Susceptible & 5 & 5 \\
Kibuzi & Susceptible & 5 & 5 \\
Nfuuka & Susceptible & 4 & 5 \\
Gonja & Susceptible & 5 & 5 \\
Kayinja & Resistant & 0 & 1 \\
M9 hybrid & Partially resistant & 2 & 3 \\
Ndiizi & Susceptible & 4 & 5 \\
\hline
\end{tabular}

dai = days after inoculation. 0-5 stage of BSD symptom development (Fullerton and Olsen, 1995)

The reaction of EAHBs was characterised by the presence of symptoms after the first 21 days (Fig. 1). The symptoms (lesions) became black or brown, with a yellow halo or chlorosis of adjacent tissues, on the upper leaf surface, and developed dry centres of grey colour in 30-55 days, similar to the behaviour of Bogoya, a reference susceptible standard for Black Sigatoka (Fig. 1). Inoculated leaves became completely necrotic, sometimes hanging down. Kayinja and M9 hybrids demonstrated resistant reactions under screenhouse conditions (Table 7).

\section{DISCUSSION}

Consistent and repeatable infection was achieved in the current study by (i) applying weighed fragmented mycelium as inoculum on the entire leaf (as opposed to a spot), and (ii) incubating the inoculated plants in a locally made humidity chamber for $48 \mathrm{hr}$ prior to placing them on a screenhouse bench, without which no infection occurred. The method reported is the first to validate the reliability of $M$. fijiensis virulence assays under ordinary screenhouse conditions 
(room temperature, average of ambient temperatures of $28{ }^{\circ} \mathrm{C}$ ) in which myccelia fragmented with a blender and weighed, were used as inoculum for artificial inoculation, as opposed to mycelia fragmented by bead beating and quantified using a heamocytometer.

This study provides a dose-dependent development of disease symptoms for three isolates of M. fijiensis. Consequently, the amount of inoculum of $M$. fijiensis used for infection studies can be measured reliably in terms of weight. Consistent infection rates were obtained by applying $500 \mu \mathrm{l}$ of a mycelium suspension of 5,10 and $15 \mathrm{mg} \mathrm{ml}^{-1}$, fragmented for $3 \mathrm{~min}$ in a blender. The mycelium-based approach for banana leaf inoculations of cv. Grosh Michel a susceptible (AAA genome group) provided reproducible and reliable results for the level of virulence of isolates Mak01, Mak02 and Kaw10. Symptom development for these isolates corresponded closely with the descriptions of Fullerton and Olsen (1995) for in vitro plants (cv. Grande Naine), inoculated with conidia. Our results are encouraging, given that Fullerton and Olsen (1995) used significantly different inoculum and inoculation conditions than what was used in our study, and yet $M$. fijiensis disease development on the two susceptible cultivars, (cv. Gross Michel and cv. Grande Naine) were comparable.

Most methods currently used for assessing disease severity for Mycosphaerella pathogens of banana, involve scales that require some degree of subjectivity (Stover and Dickens, 1970; Stover and Simmons, 1987). These systems were reviewed by Foure et al. (2000). Current methods for evaluation of Musa spp. performance in response to pathogens and pests were summarised by Carlier et al. (2003). However, none of the methods provides a direct measure of the damage caused by $M$. fijiensis on individually replicated plants under screenhouse conditions, for the purpose of identifying statistically relevant differences between host plants in disease development over time.

Occasionally, significant variability in the timing of disease symptoms on the same plant after applying the same amount of inoculum, was observed in the present study. Most likely, this was due to differences in plant leaf physiology.
The unanticipated difference in plant leaf response in these assays was taken care of by scoring the two inoculated leaves and using the average value for the two leaves in data analysis. It was, however, noted that incubation period in the emerging leaf was shorter than in fully expanded leaves. This confirmed earlier reports that younger leaves are more susceptible than older leaves (Stover, 1987).

Significant differences were observed in the cultivar response to M.fijiensis as early as four weeks after inoculation (Table 6). All East African highland banana clones were in the susceptible range of Gross Michel (Bogoya), a standard susceptible reference clone for Black Sigatoka. East African highland bananas have been reported to be in the same susceptible range with Bogaya under natural field inoculation (Tushemereirwe et al., 2004). No East African highland banana clone was found in the reaction range of Kayinja (ABB), a cultivar resistant to Black Sigatoka (Tushemereirwe et al., 2004). This confirmed an earlier report by Tushemereirwe $e t$ al. (2004) that all highland bananas are susceptible to Black Sigatoka.

The plantains (AAB), such as Gonja developed Black Sigatoka disease as fast as Bogoya, showing that it is susceptible (Fig. 3). A similar observation was made under field conditions in Uganda (Tushemereirwe et al., 2004). Ndiizi (AB group) had AUDPC values slightly lower than those for Bogoya, but overall disease development was in the rage of susceptible clones based on classification of reaction of genotypes according to symptom development (Fullerton and Olsen, 1995).

Results from previous field evaluations indicated that Ndiizi had the same number of unspotted leaves as Bogoya, suggesting that it was susceptible (Tushemereirwe et al., 2004). In the current study, Ndiizi had a long incubation period (approx. 33 days), with a rapid disease development after symptom appearance (Table 5; Fig. 3). M9 Hybrid (AAAA), specifically bred for Black Sigatoka resistance, was the only genotype with a disease reaction in the range of Kayinja (ABB).

Inoculated 4-month-old plants, incubated in local humidity chamber for $48 \mathrm{hr}$ prior to being moved to a screenhouse bench, exhibited 
elongated spots and streaks that were more typical of adult field-infected plants (Fig. 2). Previously, Pasberg-Gauhl (1994) demonstrated that disease development on very young tissueculture plants is different from field-adapted plants. Hence, the strategy of using 4-month-old plants may be more reflective of disease development and plant responses in established juvenile plants under field conditions. Under the current experimental conditions, symptoms were first observed on Grosh Michel leaves at approximately 22 DAI for both experiments 1 and 2. Depending on weather conditions and plant susceptibility, the incubation period of susceptible cultivars can be as short as 10 to 14 days under moist and favourable conditions; or as long as 35 days under dry, for less favourable conditions (Marin et al., 2003). The incubation period for susceptible juvenile plants, artificially inoculated with $M$. fijiensis, and held in greenhouses or growth chambers is between 12 and 21 days (Jacome and Schuh, 1993; Capo et al., 2003).

The relatively longer incubation period observed in this study, in comparison with other artificial inoculats reported in literature, is probably due to the use of much older plants. However, the incubation periods reported in the current study are directly comparable with those reported by Pasberg-Gauhl (1994) for 3- 8 monthold juvenile, tissue-culture derived banana plantlets grown in the field under conditions of natural infection and in a growth chamber under controlled laboratory conditions. It has further been demonstrated that the incubation period is shorter on 3 - 5-month old plants derived from tissue culture than on field-established plants (Gauhl et al., 2000). This supported the use of relatively older plants (4 to 6 months) for assaying susceptibility in the banana- $M$. fijiensis pathosystem under screenhouse conditions, as reported herein.

\section{CONCLUSION}

The use of weighed, fragmented mycelium as inoculum, applied on the abaxial surface of banana leaves and incubated for $48 \mathrm{hr}$ in a humidity chamber, is a reliable procedure for evaluating reactions of banana genotypes to $M$. fijiensis under screenhouse condition, especially in the tropics. The method is reliable and reduces the time needed to prepare inoculum by at least seven days. It is also amenable to assessment of isolate virulence, especially for those that do not sporulate profusely in vitro. Disease development using this approach requires incubation of inoculated plants in a humidity chamber (temperature of $28-31^{\circ} \mathrm{C}$ and high relative humidity) for a period of at least $48 \mathrm{hr}$ for infection to occur prior to being moved to a screenhouse. For this purpose, the present study found a simple humid chamber suitable for large-scale evaluations where quantitative assessments of disease severity can be done over the course of epidemics.

\section{ACKNOWLEDGMENT}

We thank Makerere University, Agricultural Research Institute, Kabanyolo (MUARIK) provided facilities for this study. The research was funded by the Danish International Development Agency (Danida), Denmark, through Project 09-084LIFE 'Saving a precious crop: Sustainable management of the Black Sigatoka disease of banana' and NARO, Uganda through the project "Agricultural Technology Agribusiness and Advisory Services (ATTAS)".

\section{REFERENCES}

Balint-Kurti, P.J., May, G.D. and Churchill, A. 2001. Development of a transformation system for Mycosphaerella pathogens of banana. FEMS Microbiology Letters 195:9-15.

Capo, Y.A., Mora, M.L., Rodríquez, M.A.D., Acosta, M., Cruz, M., Portal, N., Kosky, R.G., García, L., Bermudez, I. and Padron, J. 2003. Early evaluation of black leaf streak resistance by using mycelial suspensions of Mycosphaerella fijiensis. pp. 169-175. In: Mycosphaerella Leaf Spot Diseases of Bananas: Present Status and Outlook. Proceedings of the $2^{\text {nd }}$ International Workshop on Mycosphaerella leaf spot diseases, San José, Costa Rica. Jacome, L., Lepoivre, P., Marin, D., Ortiz, R., Romero, R. and Escalant, J.V. (Eds.). International 
Network for the Improvement of Banana and Plantain (INIBAP), Montpellier, France.

Carlier, J., Foure, E., Gauhl, F., Jones, D.R., Lepoivre, P., Mourichon, X., Pasberg-Gauhl, C. and Romero, R.A. 2000. Black leaf streak. pp. 37-79. In: Diseases of banana, Abacá and Enset. Jones, D.R. (Ed.). CABI Publishing, New York, USA.

Carlier, J., Waele, D.D. and Escalant, J.V. 2003. Global evaluation of Musa germplasm for resistance to Fusarium wilt, Mycosphaerella leaf spot diseases and nematodes: Performance evaluation. In: INIBAP Technical Guidelines 7. Vézina, A. and Picq, C. (Eds.). The International Network for the Improvement of Banana and Plantain, Montpellier, France.

Churchill, A.C.L. 2011. Mycosphaerella fijiensis, the black leaf streak pathogen of banana. Progress towards understanding pathogen biology and detection, disease development, and the challenges of control. Molecular Plant Pathology 12: 307-328.

Foure, E., Mourichon, X. and Jones, D.R. 2000. Black leaf streak: Host reaction evaluating germplasm for reaction to black leaf streak. pp. 62-67. In: Diseases of banana, Abacá and Enset. Jones, D.R. (Ed.). CABI Publishing, New York, USA.

Fullerton, R.A. and Olsen, T.L. 1995. Pathogenic variability in Mycosphaerella fijiensis Morelet, cause of Black Sigatoka in banana and plantain. New Zealand Journal of Crop and Horticultural Science 23: 39-48.

Gauhl, F., Pasberg-Gauhl, C. and Jones, D.R. 2000. Black leaf streak: disease cycle and epidemiology. pp. 56-62. In: Diseases of Banana, Abacá and Enset. Jones, D.R. (Ed.). CABI Publishing, New York, USA.

Jacome, L.H. and Schuh, W. 1993. Spore production and artificial inoculation techniques for Mycosphaerella fijiensis var. difformis. Tropical Agriculture (Trinidad) 70: 33-38.

Madden, L. V., Hughes, G., and van den Bosch, F. 2007. The study of plant disease epidemics.
American Phytopathological Society. St. Paul Minnesota, USA.

Marin, D.H., Romero, R.A., Guzman, M. and Sutton, T.B. 2003. Black Sigatoka: An increasing threat to banana cultivation. Plant Disease 87: 208- 222.

Pasberg-Gauhl, C. 1994. Symptom development of Black Sigatoka leaf spot on young or adult banana and plantain plants after natural inoculation. pp. 263-275. In: International Institute of Tropical Agriculture Proceeding on Biological and Integrated Control of Highland Banana and Plantain Pest and Diseases. Cotonou, Benin.

Stover, R.H. 1987. Measuring response of Musa cultivars to Sigatoka pathogens and proposed screening procedures. In: Proceedings of International Workshop on Banana and Plantain Breeding Strategies.Caims, Australia.

Stover, R. H. and Dickson, J. D. 1970. Leaf spot of bananas caused by Mycosphaerella musicola: methods of measuring spotting prevalence and severity. Troprical Agriculture 47:289-302.

Stover, R. H. and Simmons, N. W. 1987. Bananas, $3^{\text {rd }}$ Edition. Longman Group UK Ltd., Essex, UK.

Townley, A., Foundling, J., Corsten, M. and Pain, N.A. 2001. Mycosphaerella fijiensis disease development in leaves on whole plants and in a detached leaf assay. In: Caribbean Division Meeting of the American Phytopathological Society. Publication No. P-2002-0119-CRA.

Tushemereirwe, W.K., Kangire, A., Kubiriba, J., Nakyanjzi, M. and Gold, S. 2004. Field reaction of banana cultivars to Black Sigatoka disease in Uganda. African Crop Science Journal 12: 19-26.

Twizeyimana, M., Ojiambo, P.S., Tenkouano, A., Ikotun, T. and Bandyopadhyay, R. 2007. Rapid screening of Musa species for resistance to black leaf streak using in vitro plantlets in tubes and detached leaves. Plant Disease 91: 308-314. 